\title{
VIRTUAL SCREENING, PHARMACOPHORE MODELING, AND QUANTITATIVE STRUCTURE ACTIVITY RELATIONSHIP STUDIES ON HISTAMINE 4 RECEPTOR
}

\author{
SHOBANA S* \\ Department of Genetic Engineering, School of Bioengineering, SRM University, Kattankulathur, Kanchipuram - 603 203, Tamil Nadu, India. \\ Email: ksemaa@gmail.com
}

Received: 15 May 2017, Revised and Accepted: 23 August 2017

\section{ABSTRACT}

Objective: To find out novel inhibitors for histamine 4 receptor (H4R), the target for various allergic and inflammatory pathophysiological conditions.

Methods: Homology modeling of H4R was performed using easy modeler and validated using structure analysis and verification server, and with the modeled structure, virtual screening, pharmacophore modeling, and quantitative structure activity relationship (QSAR) studies were performed using the Schrodinger 9.3 software.

Results: Among all the synthetic and natural ligands, hesperidin, vitexin, and diosmin were found to have the highest dock score, and with that, a five-point pharmacophore model was developed consisting of two hydrogen bond acceptor and three ring atoms, and the pharmacophore hypothesis yielded a statistically significant three-dimensional QSAR (3D-QSAR) model with a correlation coefficient of $\mathrm{r}^{2}=0.8962$ as well as good predictive power.

Conclusion: The pharmacophore-based 3D-QSAR model generated from natural antihistamines can provide intricate structural knowledge about a new class of anti-allergic and anti-inflammatory drug research.

Keywords: Histamine 4 receptor, Homology modeling, Docking, Pharmacophore modeling, Three-dimensional quantitative structure activity relationship.

(c) 2017 The Authors. Published by Innovare Academic Sciences Pvt Ltd. This is an open access article under the CC BY license (http://creativecommons. org/licenses/by/4. 0/) DOI: http://dx.doi.org/10.22159/ajpcr.2017.v10i12.19991

\section{INTRODUCTION}

Histamine is a small molecule derived from the decarboxylation of the amino acid called histidine. These histamine molecules are synthesized in all tissues but are mainly abundant in the skin, gastrointestinal tract, and lungs. The prominent source of this histamine is mast cells and other immune cells. When the allergen or antigen cross-links with IgE on the surface of immune cells, it responds by the liberating histamine molecules. Histamine [1-7], a chemical messenger, exerts many numerous physiological processes in hypersensitivity responses, gastric acid secretion, neurotransmission, immunomodulation, cell differentiation, and embryonic development through four distinct receptors: H1R, H2R, H3R, and H4R, which belong to class of $G$ protein-coupled receptors (GPCR) [8-14]. Histamine is best known as a mediator of allergic reactions and now recognized to participate in numerous other pathologic processes. The sensitivity of histamine depends on the type of receptor. It is mainly expressed in mast cells, monocytes, eosinophils, dendritic, and T-cells. Histamine 4 receptor, a type of G-protein coupled histamine receptor family identified in recent times, commonly known as H4R. The histamine receptors are differentially expressed in various cell types which when binds to a small biogenic amine molecule called histamine leads to various pathophysiological regulatory role in cellular events. H4R is expressed in numerous cells and tissues of immune system, especially in the hematopoietic sources; in other words, it is present in bone marrow, spleen, thymus, lung, and colon. As it is highly expressed in peripheral blood cells and intestinal tissues, the activation of the $\mathrm{H} 4$ receptor by the binding of histamine molecule enhances the activity of several chemoattractants and leads to chemotaxis, eosinophil, and neutrophil trafficking which causes inflammation. This in turn makes $\mathrm{H} 4$ receptor a potential target of allergic and inflammatory disorders. It is a recently identified histamine receptor due to complications in crystallization process; the crystal structure of H4R is not available yet.
Hence, the unexplored biochemical activities and necessity to inhibit the histamine binding attracted biologist, thus serving as a novel target for pharmacological modulation of histamine-transferred immune signals. The unexplored biochemical activities attract biologist, and it serves as a novel target for pharmacological modulation of histaminetransferred immune signals. H4R shows $35 \%$ homology to H3R. H4R [7,15-20] mainly distributes in hematopoietic cells and plays a key role in nociceptive responses, autoimmune disorder, allergic conditions, colon cancer, and breast cancer. H4R belongs to the super family of GPCR. In connection with efforts rendered in finding out novel inhibitors for H4R, we perform virtual screening and docking studies, and with the best ligands, we have created a pharmacophore model, and quantitative structure activity relationship (QSAR) studies were performed.

\section{METHODS}

\section{Homology modeling}

The crystal structure of histamine 4 is not available in protein data bank (PDB). Hence, we developed the optimized model of H4R with the help of Easy Modeler. Hence, the crystal structure of histamine 1 which has been identified very recently is downloaded from the PDB (PDB ID 3RZE). This is used as template to construct the H4R model. The H4R sequence is retrieved from Gen Bank (Accession no Q9H3N8). The model that is generated is then energy minimized. The optimized model is then validated using structure analysis and verification server.

\section{Molecular docking}

Protein preparation

Preparation of the target protein using 'protein preparation wizard'. Pre-processing and heterostate for co-crystallized ligand were generated using Epik; protonation state and optimization of H-bonding of the protein side chains were assigned using protassign, energy 
minimized (impref minimization) using optimized potential for liquid simulations (OPLS) 2001 force field. Receptor grid has been prepared with default parameters and without any constraints.

\section{Ligand preparation}

The ligands required for docking exported as a single file and are prepared by using the tool LigPrep utility of Schrodinger suite with default parameters, the ligand energy minimized by using OPLS 2005 (macromodel multiple minimization) and water as solvent. Ligand docking was performed using OPLS force field. To predict the binding affinity and preeminent docked structures, the combined ligand docking and energy grid scores were ranked by using Emodel and glide scores.

\section{Ligand docking}

Flexible docking was performed using the extra precision feature of glide 5.0 module implemented in the Schrodinger LLC. Visualization and analysis of protein-ligand complexes were performed using PyMOL ver. 0.99 software (DeLano Scientific LLC, CA, USA), and the best-docked ligand will be classified based on the glide score.

Phase methodology dataset and biological activity.

We take 11 natural antihistamines from literature studies, and their inhibitory concentration $\left(\mathrm{IC}_{50}\right)$ values are converted into $\mathrm{p} \mathrm{IC}_{50}$ using following formula: $\mathrm{p} \mathrm{IC} \mathrm{I}_{50}=-\log \mathrm{IC}_{50}$ (Table 1).

Creating pharmacophore sites and common pharmacophore hypothesis $(\mathrm{CPH})$ generation

The molecules are divided into actives and inactives according to the $p$ $\mathrm{IC}_{50}$ values. The phase consists of the pharmacophore features such as hydrogen bond acceptor (A), hydrogen bond donor (D),hydrophobic/ non-polar group $(\mathrm{H})$, negatively ionizable $(\mathrm{N})$, positively ionizable $(\mathrm{P})$, and aromatic ring (R) which is used to create the pharmacophore sites for the ligands. The $\mathrm{CPH}$ is examined using scoring hypothesis.

\section{Scoring function}

The measurement of quality of alignment is done by means of survival score given as:

\section{S=WsiteSsite+WvecSvec+WvolSvol+WselSsel+Wm rew}

Where W denotes weights, S denotes scores, Ssite represents alignment score, Svec represents vector score which is the averages of the cosine of the angles formed by corresponding pairs of vector features in aligned structures, Svol represents volume score which is based on overlap of Vander Waals models of non-hydrogen atoms in each pair of structures, and Ssel represents selectivity score, and this accounts for what fraction of molecules is likely to match the hypothesis regardless of their activity toward the receptor. The default values for Wsite, Wvec, Wvol, and Wrew are 1.0, whereas the default value for Wsel is 0.0 .We have used the default values in all the cases for our hypothesis generation.

Table 1: Compounds with $\mathrm{IC}_{50}$ values

\begin{tabular}{ll}
\hline Compounds & IC $_{\mathbf{5 0}}$ \\
\hline Hesperidin & 9.5 \\
Vitexin & 46.5 \\
Rutin & 12.3 \\
Chlorogenic acid & 45.5 \\
Quercetin & 15.4 \\
Myricetin & 2.12 \\
Fisetin & 3.7 \\
3-methyl quercetin & 2.75 \\
Luteolin & 18.6 \\
Catechin & 49 \\
Kaempferol & 0.84 \\
\hline
\end{tabular}

$\mathrm{IC}_{50}$ : Inhibitory concentration

\section{Atomic three-dimensional QSAR (3D-QSAR) generation}

The QSAR models were developed from a series of molecules, of varying activity, that have all been aligned to a $\mathrm{CPH}$ that is associated with a single reference ligand. All hypotheses that successfully generated and scored were then used to build pharmacophore-based 3D-QSAR models with grid spacing 1.0 A. PHASE supports only external validation, using a factual test set for which structures and activities are not considered for developing QSAR models. The developed 3D-QSAR models are validated by predicting activities of test set molecules which are measured in terms of Q-square values. The predictive ability of the developed models is measured by means of the Pearson correlation coefficient $r$ value.

\section{RESULTS AND DISCUSSION}

\section{Homology modeling}

The Ramachandran plot obtained from procheck showed that $90.9 \%$ of the residues were found to be in the most favored regions, indicating that our model was good (a good quality model would be expected to have over $90 \%$ in the most favored regions), and only $0.3 \%$ of the residues were found to be present in disallowed region. Thus, out of 390 residues, 328 residues were found in most favored regions, and only one residue was in the disallowed region (Fig. 1) [21-23]

\section{Molecular docking studies}

The active sites are predicted based on literature studies and the amino acids include Asp94, Tyr95, Glu182, Thr316, Thr319, and Phe344 [24]. The interactions of H4R with both natural and synthetic ligands are analyzed. In case of synthetic ligands, the common amino acids that interacted with histamine were Tyr95 and Thr323 (Table 2). In case of natural ligands, the common amino interactions were Tyr95, Glu182, Thr323, and Ser362 (Table 3).

In light of good docking score (glide score) and a number of hydrogen bonds shown by docking analysis in the comparison, following compounds show better efficiency: Hesperidin, vitexin, and diosmin such as $13.71 \mathrm{kcal}^{-1},-11.34 \mathrm{kcal}^{-1}$, and $-10.87 \mathrm{kcal}^{-1}$, respectively (Fig. 2). These natural compounds showing their best efficiency could be thus used as potential leads in drug designing. Furthermore, the natural compounds are found to be better inhibitors of H4R when compared to synthetic ligands based on the glide score. Thus, natural compounds can be more effective when used in the treatment of disease when compared to synthetic compounds [25].

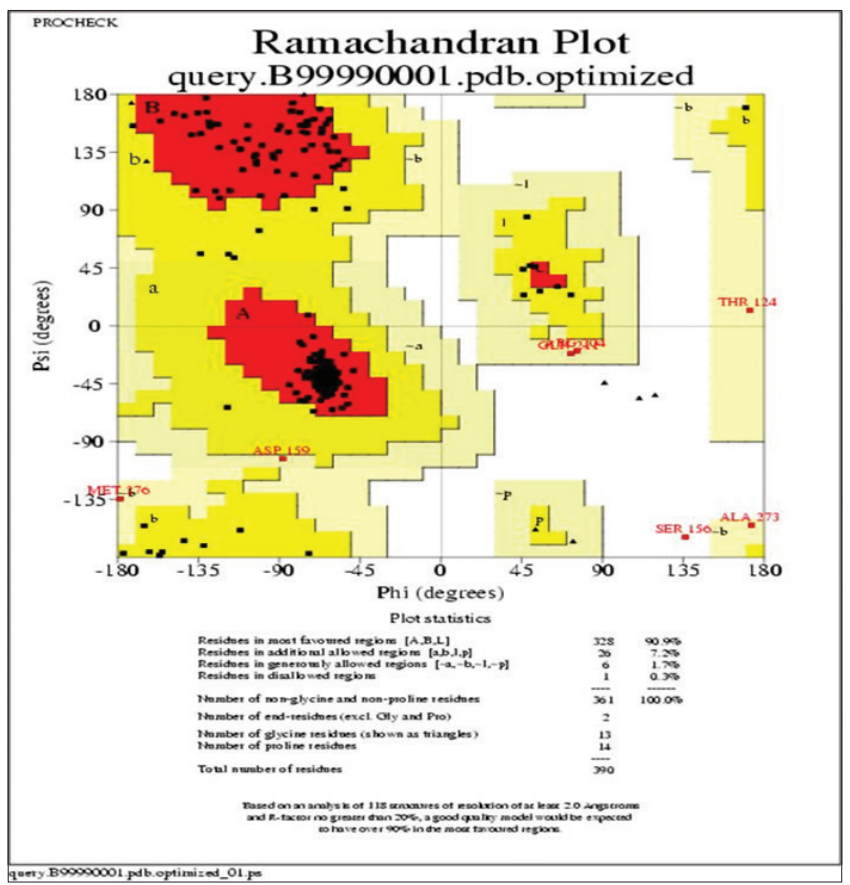

Fig. 1: Ramachandran plot result of homology-modeled protein 
Table 2: Docking result of chemical inhibitors

\begin{tabular}{|c|c|c|c|c|}
\hline Name & Cid number & Glide score & H-bond length & Amino acid interaction \\
\hline Diphenhydramine & 3100 & -6.75 & $2.353,2.314$ & TYR 95, TYR 319 \\
\hline A-943931 & 25068753 & -6.72 & $2.315,2.341,2.410$ & TYR 95, GLU 182 \\
\hline Thioperamide & 3035905 & -6.32 & 1.813 & THR 323, TYR 340 \\
\hline JNJ-10191584 & 10446295 & -5.73 & $2.584,1.669$ & SER 179, THR 323 \\
\hline JNJ-7777120 & 4908365 & -5.67 & 1.756 & TYR 95 \\
\hline Cetirizine & 2678 & -5.42 & $2.623,1.717$ & THR 323, SER 320 \\
\hline Clemastine & 26987 & -1.65 & & No interaction \\
\hline Histamine & 774 & -6.54 & & ASP 94, GLU 163, SER 162, TYR 95 \\
\hline
\end{tabular}

Table 3: Docking result of natural ligands

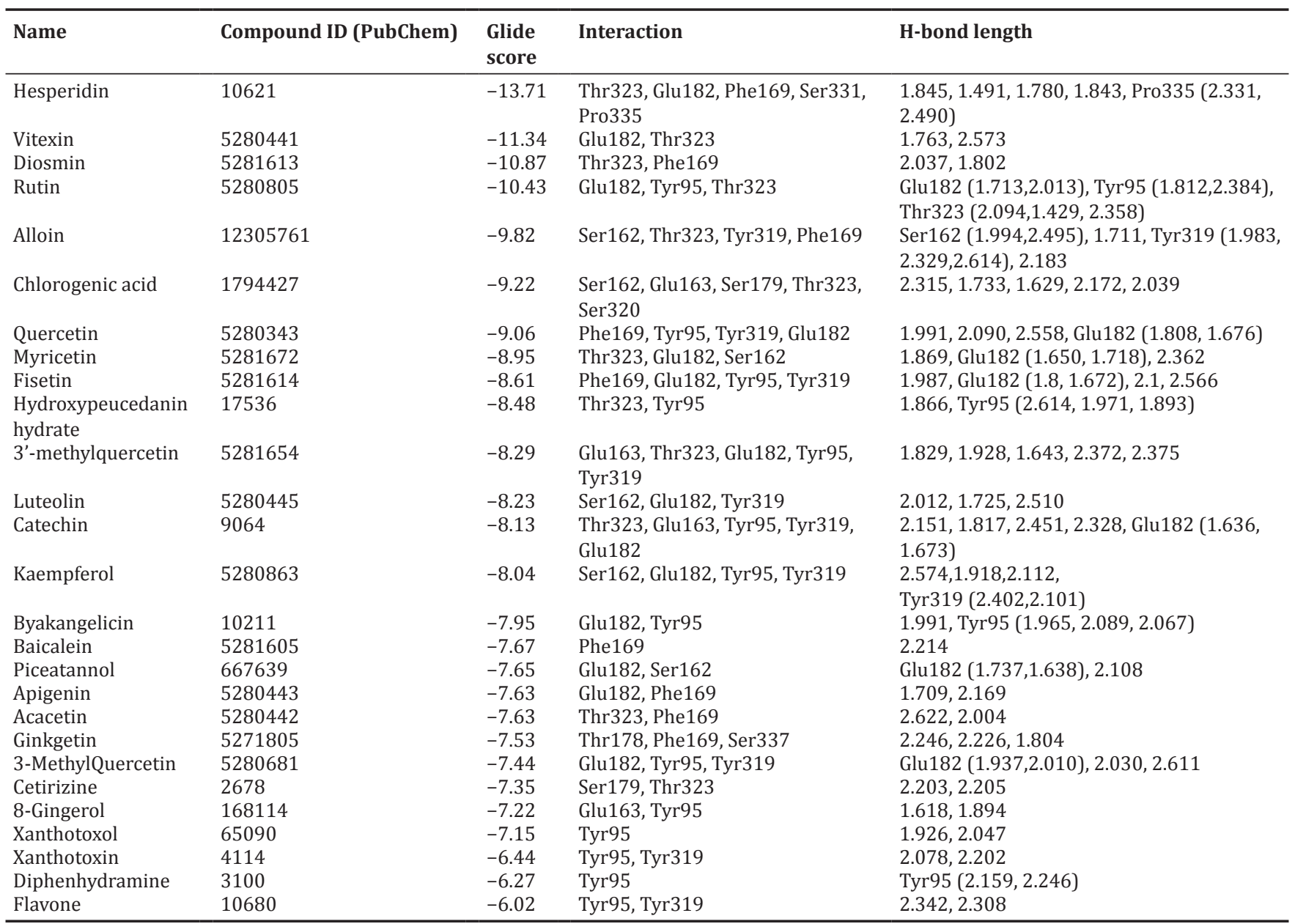

Pharmacophore hypothesis

Pharmacophore modeling studies were done using $\mathrm{IC}_{50}$ values of the top scoring natural antihistamines, and subsequently a pharmacophore compound consisting of 7 essential pharmacophoric features of three Hydrogen bond Donor, two hydrogen bond Acceptor and two hydrophobic ring structure was developed (Fig. 3), (Table 4).

The crystal energy is minimized using the OPLS 2005 force field energy. The ligands are built using Maestro build panel and prepared by a LigPrep 2.2 module, which uses OPLS 2005 force field to produce the lowest energy conformer of ligands. The training and test set were selected randomly, and the seed value for activity threshold given was 8.432 to ensure that the assignment is randomly done (Fig. 4).

Due to various difficulties in the crystallization of GPCR protein, the crystal structure of H4R is not yet solved. The crystal structure of human histamine H1R is reported very recently. Hence, we developed
Table 4: Pharmacophore features of the compound selected

\begin{tabular}{llllll}
\hline Rank & $\begin{array}{l}\text { Feature } \\
\text { label }\end{array}$ & Score & Type & Number & Source \\
\hline 1 & R27 & -1.26 & R & 26 & Aromatic ring \\
2 & D18 & -0.96 & D & 17 & H phobe \\
3 & D20 & -0.96 & D & 19 & $\begin{array}{l}\text { H Bond } \\
\text { H Bond }\end{array}$ \\
4 & R26 & -0.94 & R & 25 & $\begin{array}{l}\text { Ring chem score } \\
\text { H phobe }\end{array}$ \\
5 & & & & & H Bond \\
6 & A9 & -0.78 & A & 8 & H Bond \\
7 & D11 & -0.48 & D & 22 & PhobEn+H Bond \\
\hline
\end{tabular}

a homology model of H4R based on the crystal structure of H1R [15]. Then, several synthetic and natural ligands including agonists and antagonists are docked in the H4R model [15]. The synthetic and natural 
Table 5: Statistical data for best QSAR model by the PLS method for natural antihistamines

\begin{tabular}{lllllll}
\hline Hypothesis ID & Survival score & $\mathbf{R}^{2}$ value & RMSE values & F & Q & Palue \\
\hline AAARR. 4 & 3.906 & 0.8533 & 0.4914 & 29.1 & 0.45 \\
AADRR. 112 & 3.906 & 0.759 & 0.3363 & 15.7 & 0.483 \\
ADRRR. 4 & 3.914 & 0.7308 & 0.2788 & 13.6 & 0.4989 \\
AARRR. 16 & 3.914 & 0.8962 & 0.6611 & 34.5 & 0.451 \\
\hline
\end{tabular}

QSAR: Quantitative structure activity relationship, RMSE: Root-mean-square error, $\mathrm{R}^{2}$ : The coefficient of determination, $\mathrm{Q}^{2}$ : Cross-validated $\mathrm{R}^{2}$, $\mathrm{F}$ : $\mathrm{F}$ test score,

R: Correlation between experimental and predicted activity for the test set
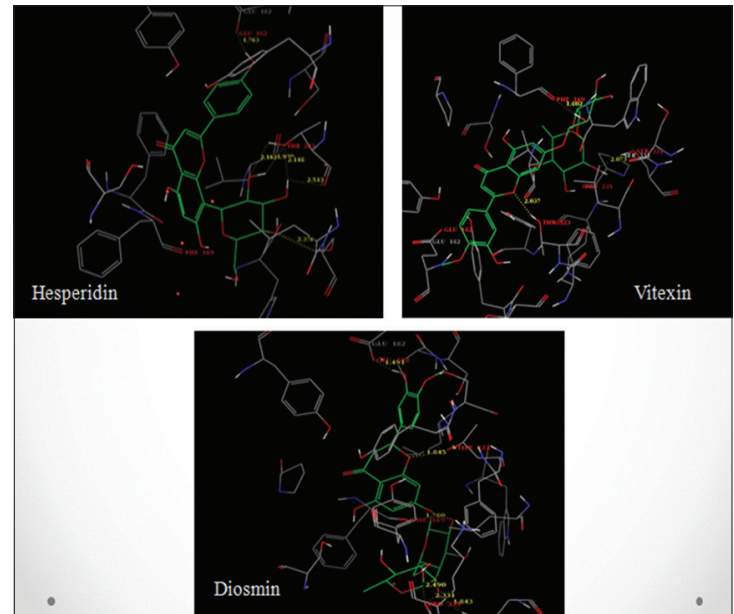

Fig. 2: Interaction of the three top scored natural ligands in the binding pocket of target molecules

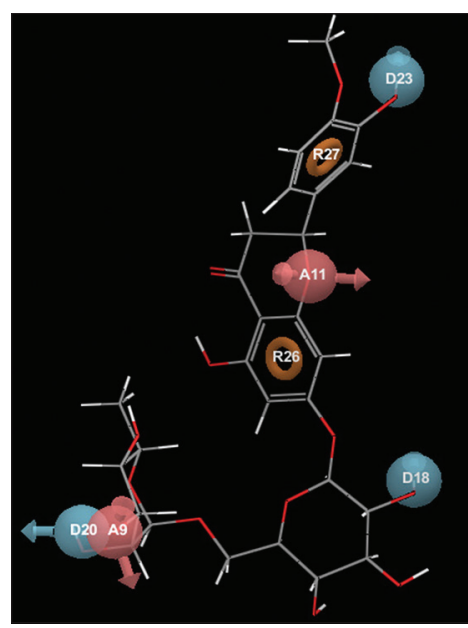

Fig. 3: The pharmacophore hypothesis where the red ball denotes hydrogen bond donor and brown ring denotes ring feature

ligands are collected from literature searches and Duke's phytochemical database, respectively. The interaction of ligands with the model is analyzed, and based on the docking score, potential ligand is identified. Pharmacophore modeling studies are done using $\mathrm{IC}_{50}$ values of 11 natural antihistamines which are collected from the literature. Thus, a five-point pharmacophore model is developed. The pharmacophore hypothesis is then used to yield a statistically significant 3D-QSAR model with a good correlation coefficient and predictive power [23-32] (Table 5).

\section{CONCLUSION}

In light of good glide score, it can be concluded that the natural antihistamines such as hesperidin, vitexin, and diosmin show better efficiency when compared to synthetic compounds and could be used as potential leads in drug designing against $\mathrm{H} 4$ receptor to treat

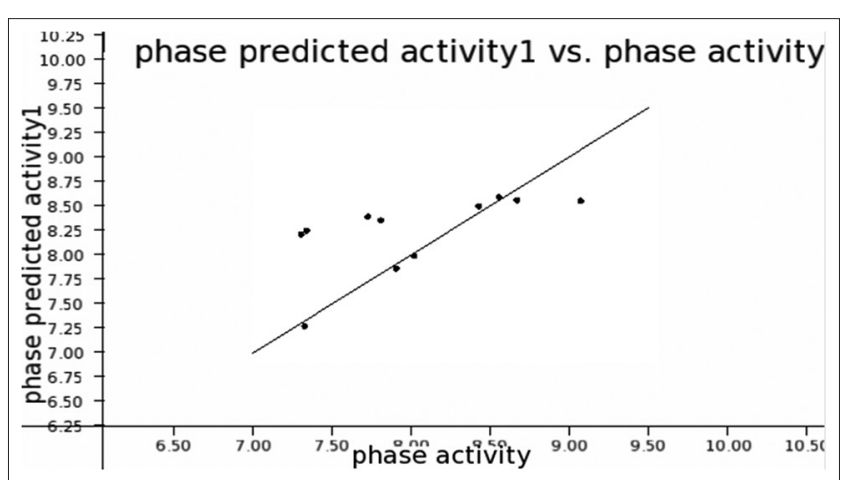

Fig. 4: The scatter plots of quantitative structure activity relationship model applied to all compounds in the training and test set

various allergic and inflammatory diseases. The pharmacophore-based 3D-QSAR model generated from natural antihistamines can provide intricate structural knowledge about a new class of anti-allergic and anti-inflammatory drug research. The developed pharmacophore model can help us in virtual screening of finding new potent ligands against allergy which can help us in the better therapy of allergic conditions.

\section{REFERENCES}

1. Parsons ME, Ganellin CR. Histamine and its receptors. Br J Pharmacol 2006;147 Suppl 1:S127-35.

2. Akdis CA, Simons FE. Histamine receptors are hot in immunopharmacology. Eur J Pharmacol 2006;533(1-3):69-76.

3. Hong ST, Bang S, Paik D, Kang J, Hwang S, Jeon K, et al. Histamine and its receptors modulate temperature-preference behaviors in Drosophila. J Neurosci 2006;26(27):7245-56.

4. Sander LE, Lorentz A, Sellge G, Coëffier M, Neipp M, Veres T, et al. Selective expression of histamine receptors H1R, H2R, and H4R, but not H3R, in the human intestinal tract. Gut 2006;55(4):498-504.

5. Szukiewicz D, Szewczyk G, Klimkiewicz J, Pyzlak M, Maslinska D. The role of histamine and its receptors in the development of ovarian follicles in vitro. Inflamm Res 2006;55 Suppl 1:S49-50.

6. Breunig E, Michel K, Zeller F, Seidl S, Weyhern CW, Schemann M. Histamine excites neurones in the human submucous plexus through activation of H1, H2, H3 and H4 receptors. J Physiol 2007;583:731-42.

7. Zampeli E, Tiligada E. The role of histamine H4 receptor in immune and inflammatory disorders. Br J Pharmacol 2009;157(1):24-33.

8. Li YY, Hou TJ, Goddard WA $3^{\text {rd }}$. Computational modeling of structurefunction of $\mathrm{g}$ protein-coupled receptors with applications for drug design. Curr Med Chem 2010;17(12):1167-80.

9. Li Y, Hou T. Computational simulation of drug delivery at molecular level. Curr Med Chem 2010;17(36):4482-91.

10. Goddard WA $3^{\text {rd }}$, Kim SK, Li Y, Trzaskowski B, Griffith AR, Abrol R. Predicted 3D structures for adenosine receptors bound to ligands: Comparison to the crystal structure. J Struct Biol 2010;170(1):10-20.

11. Kim SK, Li Y, Abrol R, Heo J, Goddard WA $3^{\text {rd }}$. Predicted structures and dynamics for agonists and antagonists bound to serotonin 5-HT2B and 5-HT2C receptors. J Chem Inf Model 2011;51(2):420-33.

12. Li Y, Zhu F, Vaidehi N, Goddard WA $3^{\text {rd }}$, Sheinerman F, Reiling S, et al. Prediction of the 3D structure and dynamics of human DP G-protein coupled receptor bound to an agonist and an antagonist. J Am Chem Soc 2007;129(35):10720-31. 
13. Kim SK, Li Y, Park C, Abrol R, Goddard WA $3^{\text {rd }}$. Prediction of the three-dimensional structure for the rat urotensin II receptor, and comparison of the antagonist binding sites and binding selectivity between human and rat receptors from atomistic simulations. Chem Med Chem 2010;5(9):1594-608

14. Kottke T, Sander K, Weizel L, Schneider EH, Seifert R, Stark H. Receptor-specific functional efficacies of alkyl imidazoles as dual histamine $\mathrm{H} 3 / \mathrm{H} 4$ receptor ligands. Eur J Pharmacol 2011;654(3):200-8.

15. Cowart MD, Altenbach RJ, Liu H, Hsieh GC, Drizin I, Milicic I, et al. Rotationally constrained 2,4-diamino-5,6-disubstituted pyrimidines: A new class of histamine $\mathrm{H} 4$ receptor antagonists with improved druglikeness and in vivo efficacy in pain and inflammation models. J Med Chem 2008;51(20):6547-57.

16. Smits RA, Adami M, Istyastono EP, Zuiderveld OP, van Dam CM, de Kanter FJ, et al. Synthesis and QSAR of quinazoline sulfonamides as highly potent human histamine H4 receptor inverse agonists. J Med Chem 2010;53(6):2390-400.

17. Thurmond RL, Desai PJ, Dunford PJ, Fung-Leung WP, Hofstra CL, Jiang W, et al. A potent and selective histamine $\mathrm{H} 4$ receptor antagonist with anti-inflammatory properties. J Pharmacol Exp Ther 2004;309(1):404-13.

18. Terzioglu N, van Rijn RM, Bakker RA, De Esch IJ, Leurs R. Synthesis and structure-activity relationships of indole and benzimidazole piperazines as histamine $\mathrm{H}(4)$ receptor antagonists. Bioorg Med Chem Lett 2004;14(21):5251-6.

19. Shimamura T, Shiroishi M, Weyand S, Tsujimoto H, Winter G, Katritch V, et al. Structure of the human histamine H1 receptor complex with doxepin. Nature 2011;475(7354):65-70

20. Zhang M, Thurmond RL, Dunford PJ. The histamine H(4) receptor: A novel modulator of inflammatory and immune disorders. Pharmacol Ther 2007;113(3):594-606.

21. Vijayasri S, Hopper W. Towards the identification of novel phytochemical leads as macrodomain inhibitors of chikungunya virus using molecular docking approach. J Appl Pharm Sci 2017;4:74-82.

22. Walter M, Kottke T, Stark H. The histamine H4 receptor: Targeting inflammatory disorders. Eur J Pharmacol 2011;668(1-2):1-5.

23. Kiss R, Noszál B, Rácz A, Falus A, Eros D, Keseru GM. Binding mode analysis and enrichment studies on homology models of the human histamine H4 receptor. Eur J Med Chem 2008;43(5):1059-70.

24. Feng Z, Hou T, Li Y. Docking and MD study of histamine H4R based on the crystal structure of H1R. J Mol Graph Model 2013;39:1-12.

25. Kiss R, Kovári Z, Keseru GM. Homology modelling and binding site mapping of the human histamine $\mathrm{H} 1$ receptor. Eur J Med Chem 2004;39(11):959-67.

26. Banerjee S, Sen D. Pharmacophore based atomic QSAR study of novel quinaxaline 1, 4-di-N-oxides as selective non-cytotoxic anti-tubercular agents. Int J Chem Stud 2013;1:110-7.

27. Ugale VG, Patel HM, Surana SJ. Molecular modeling studies of quinoline derivatives as VEGFR-2 tyrosine kinase inhibitors using pharmacophore based 3D QSAR and docking approach. Arab J Chem 2017;10:S1980-2003.

28. Devi B, Rajagopala K, Elizabeth E. Pharmacophoric screening of various edophytic fungal metabolites. Asian J Pharm Clin Res 2017;10:140-6.

29. Devi SK, Velmurugan D. Molecular modelling, QSAR and pharmacophore studies on anti-viral, anti-malarial and antiinflammatory bioactive compounds from marine sources. Asian J Pharm Clin Res 2015;8:3.

30. Dharani RS, Ranjitha R, Sripathi R, Muhammad KA, Ravi S. Docking studies in target proteins involved in antibacterial action mechanisms: Alkaloids isolated from Scutellaria genus. Asian J Pharm Clin Res 2016;9:5.

31. Al-Jomaily M, Arafat T, Al-Kaissi E, Ghattas MA, Muhi-Eldeen Z. Synthesis of amino acetylenic benzophenone derivatives as H3-antagonists. Int J Pharm Pharm Sci 2015;7:6.

32. Kaur G, Singh R. Thiadiazole analogs as potential pharmacological agents: A brief review. Int J Pharm Pharm Sci 2014;6:8. 